\title{
"Once You Know Something, You Can't Not Know It" An Empirical Look at Becoming Vegan
}

\begin{abstract}
In spite of a growing body of vegetarian literature, there remains a lack of information about how people learn to become vegan. Using qualitative methodology, this research identified a psychological process of how people learn about and adopt veganism. Elements of the process include who I was, catalytic experiences, possible repression of information, an orientation to learn, the decision, learning about veganism, and acquiring a vegan world view. Noteworthy observations include individual and temporal variation in the use of logic and emotion, the centrality of reading, the repression and recollection of undesirable information, and the importance of two types of learning tasks to successful vegans.
\end{abstract}

Vegans are people who object to the use of nonhuman animal products for food, cosmetics, clothing, and vivisection - virtually all invasive activities involving nonhuman animals. In the United States, adopting such a lifestyle is a major change from the normative practice and ideology of human dominance over nonhuman animals. Veganism appears to be related to a propensity toward alternativism in other areas of life (Hamilton, 1993), and eschewing the use of all animal products represents a lifestyle

Society \& Animals 8:1 (2000)

(C) Koninklijke Brill NV, Leiden, 2000 
change that necessarily involves all areas of life. How do people make such a remarkable change? A possible explanation might be offered by Mezirow's transformation theory (Mezirow, 1991, 1995, 1998), which predicts that such lifestyle change will follow a ten-step process that pivots on dialogue, reflection, and action.

Mezirow's transformation theory has been widely discussed in adult education as an explanation of how adults learn to make major lifestyle changes. The ten steps, which Mezirow says can occur in any order, include a disorienting dilemma, self-examination, and critical assessment of assumptions. They also include recognizing that discontent and transformative experiences are shared, exploring new options, planning a course of action, acquiring new skills and knowledge, trying new roles, renegotiating relationships and building new ones, and reintegrating the new perspective into one's life. A central triad, upon which the ten steps depend, includes critical reflection, democratic dialogue, and reflective action.

As part of a larger study, I discovered that Mezirow's theory does not explain the process of learning to become vegan (McDonald, 1998). The research presented here is in answer to the question, "How do people learn to become vegan?" - the first question in my investigation of Mezirow's transformation theory.

An online literature search of publications in education, psychology, and social sciences failed to find research on how people learn to become vegetarian or vegan. In fact, I found no reference to any social science research using the keywords vegan or veganism. Vegetarian literature was more numerous (Adams, 1995; Beardsworth \& Keil, 1992, 1993; Dietz, Frisch, Kalof, Stern, \& Guagnano, 1995; George, 1994; Hamilton, 1993; Rozin, Markwith, \& Stoess, 1997; Walker, 1995). None of these articles, however, focused on the learning process. One study reported four reasons for becoming vegetarian, including personal health, concern with animal cruelty, concern for world hunger, and environmental concern (Dietz, Frisch, Kalof, Stern, \& Guagnano, 1995). Krizmanic (1992) reported that almost $25 \%$ of vegetarians surveyed said that animal welfare, the environment, or ethics was the most important reason for adopting their diet. Vegetarianism was also explored as a case study of moralization, in which previously morally neutral objects or activities become moral (Rozin, Markwith, \& Stoess, 1997).

2 - Barbara McDonald 
These studies, however, do not shed light on the process of how some people become vegetarian. Even more intriguing is why some vegetarians become vegans and others do not, considering that most vegetarians have access to information about the similarities and interrelationship between the meat and dairy industries. Stepaniak (1998) noted that the ethical position of vegans differentiates them from vegetarians: "Because veganism encompasses all aspects of daily living, not just diet, it is inaccurate for people to define themselves as [vegan] simply because they have adopted the vegan mode of eating" (p. 21).

Becoming vegan represents a major change in lifestyle, one that demands the rejection of the normative ideology of speciesism. With only $3 \%$ of Americans claiming they had not used animals for any purpose within the previous two years (Duda \& Young, 1997), veganism represents an alternative ideology and lifestyle (Hamilton, 1993). How do people learn about this alternative ideology, and how do they learn to change their lifestyle?

\section{Method}

As a practicing vegan, I wanted to employ a perspective and methodology that would enable me to use my own experience to enhance understanding of how other vegans have learned; yet I wanted the story to be their own. My adoption of veganism, following years as a vegetarian and animal rights activist, was triggered by the loss of a long-time canine companion. My journey as a vegan in mainstream society and my familiarity with the personal and social issues surrounding veganism informed the interview protocol and data analysis.

However, because I wanted to know the path that others had traveled, I chose a phenomenological perspective. Typically in phenomenology, the researcher attempts to remove his or her biases from the research. To enable the incorporation of my own understanding, I chose heuristics, a modification of phenomenological methodology (Moustaskas, 1990). Heuristics explicitly recognizes the impossibility of neutrality in research and enables the researcher to study phenomena with which he or she has had intense experience.

I used a naturalistic design to collect interview data from twelve vegans. Purposeful sampling was used, beginning with the June 1996 nationwide

$$
\text { An Empirical Look at Becoming Vegan - } 3
$$


March for the Animals in Washington, DC. I employed snowball sampling to further identify vegans from a small core of vegans identified at the March. To increase the probability of interviewing committed vegans, I interviewed only those who had been vegan for at least one year (Table 1). I used an unstructured interview protocol, with the primary purpose of allowing each participant to share the story of how he or she learned to adopt a vegan lifestyle. Although I asked for clarification or elaboration regarding their learning, most of my contribution to the interviews was to keep the participants from straying away from their stories.

Table 1

The Participants

\begin{tabular}{|c|c|c|c|c|c|}
\hline \multirow[t]{2}{*}{ Participant } & \multirow[b]{2}{*}{ Age } & \multirow[b]{2}{*}{ Sex } & \multicolumn{2}{|c|}{ Number of Years } & \multirow[b]{2}{*}{ Profession } \\
\hline & & & Vegetarian & Vegan & \\
\hline Cary & 31 & M & $\sim 12$ & $\sim 10$ & $\begin{array}{l}\text { Attorney/Real estate } \\
\text { Developer }\end{array}$ \\
\hline Drew & 26 & M & 6 & 5 & $\begin{array}{l}\text { Youth counselor/Former } \\
\text { army ranger }\end{array}$ \\
\hline Franz & 38 & M & 16 & 7 & University professor \\
\hline Janet & 52 & F & 7 & 7 & $\begin{array}{l}\text { Law student/Former } \\
\text { occupational therapist }\end{array}$ \\
\hline Lanny & 40 & M & 2.5 & 2 & Structural architect \\
\hline Lena & $40^{\prime} \mathrm{s}$ & $\mathrm{F}$ & $\sim 14$ & -13 & Graphic artist \\
\hline Lisa & 42 & $\mathrm{~F}$ & 1.5 & 1.5 & Secretary \\
\hline Lucille & 85 & $F$ & $\sim 6$ & $\sim 5$ & Grandmother \\
\hline Michelle & $60^{\prime} \mathrm{s}$ & $F$ & 10 & $\mathrm{~N} / \mathrm{A}$ & Wife/grandmother \\
\hline Sean & 23 & M & 5 & 4 & Tattoo artist \\
\hline Roger & 23 & M & 6 & $\sim 4$ & Body piercer \\
\hline $\begin{array}{l}\text { Maire and Will } \\
\sim=\text { Approxima }\end{array}$ & $40^{\prime} \mathrm{s}$ & $\mathrm{F} \& \mathrm{M}$ & 7 & $\sim 4$ & Secretary/Corporate mgr. \\
\hline
\end{tabular}

4 - Barbara McDonald 
I first read the interviews in their entirety, noting initial impressions. I constructed a narrative of each participant's story, which I sent to the participant for review. Open and axial coding were used to create categories, following the procedure outlined in Strauss and Corbin (1990). Following axial coding, I employed the paradigm model to organize the emergent categories around a central phenomenon. Strauss and Corbin (1990) recommended that the researcher tell the collective story analytically, based on the results of the categorical organization. I found it more productive to develop the collective story from the initial narratives, constructed in the form of a schema, from the first reading. I checked each narrative against this collective schema. Then I enlisted three participants to review the schema, asking them if it rang true from their perspective. The resulting model is a psychological schema of the process of how these vegans learned about veganism and how they adopted a vegan lifestyle.

\section{Findings}

The Process of Learning to Become Vegan

The process of learning to become vegan was rooted in the individuals' sense of who they are and how they fit in the world. During the learning process, the individual passed through a number of experiences diagrammed schematically as a general process of learning to become vegan (Figure 1). The elements are described below and defined in Table 2 .

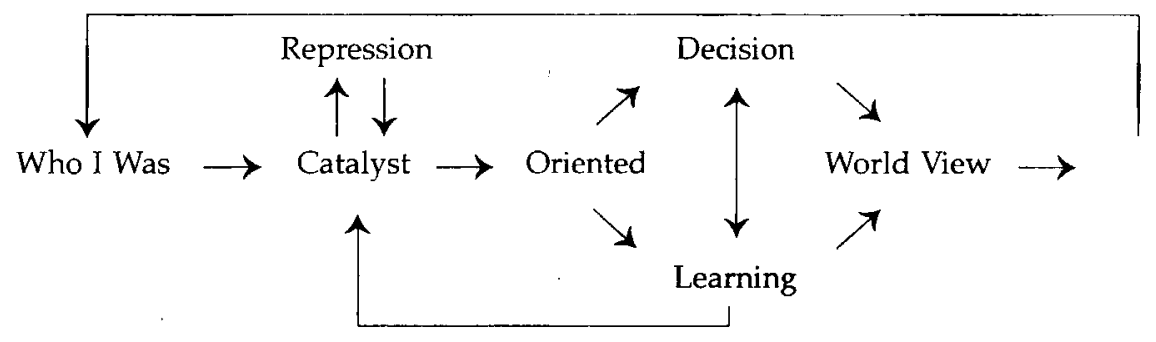

Figure 1. The Process of Learning to Become Vegan.

An Empirical Look at Becoming Vegan - 5 
Table 2

Elements of the Vegan Learning Process

\begin{tabular}{|c|c|c|}
\hline Who I Was & - & $\begin{array}{l}\text { The background and experiences that made the participa who } \\
\text { they were prior to the learning experience. }\end{array}$ \\
\hline Catalytic Experience & - & $\begin{array}{l}\text { The experience that introduced the participant to some aspect } \\
\text { of animal cruelty, and resulted in repression or becoming } \\
\text { oriented. }\end{array}$ \\
\hline Repression & - & The repression of knowledge. \\
\hline Becoming Oriented & - & The intention to learn more, make a decision, or do both. \\
\hline Learning & - & $\begin{array}{l}\text { Learning about animal abuse or how to live as a vegetarian or } \\
\text { vegan. }\end{array}$ \\
\hline Decision & - & Making the choice to become vegetarian or vegan. \\
\hline World View & - & The new perspective that guides the vegan's new lifestyle. \\
\hline
\end{tabular}

Each individual came to the learning event with a unique personal and cultural history, identified in this study as who I was. These histories shaped their original world views and, for most of the participants, influenced their learning to become vegan. For example, most of the participants claimed to have been "animal people" all their lives, which they felt may have helped them become more receptive to information about animal cruelty.

Information on cruelty served as a catalyst to one of two reactions. In two cases, individuals reported a reaction interpreted as repression. These participants put the information in the back of their minds until a later time, when another catalytic event facilitated its recall. A second, more common reaction was to become oriented in one of two ways: either to learn more about animal cruelty or to decide to become vegetarian or vegan and, subsequently, to learn more about animal cruelty and how to live as a vegetarian or vegan.

The participant typically spent a fair amount of time, even years, learning about animal cruelty or how to live as a vegetarian or vegan. If oriented to learn about cruelty but undecided about becoming a vegetarian or vegan, the participant made the decision after a period of learning about animal cruelty.

Over time, the participant adopted a world view characteristic of vegans, represented by a belief in the equality of human and nonhuman animals. This

6. Barbara McDonald 
world view became the foundation for an ethically-based praxis. The following discussion examines each stage of the process in more detail.

\section{Participants' Testimonies}

Who were these people before they became vegans? Most of the participants had a prior love of nature and of "pets" but did not see the connection between their companion animals and food animals. Before becoming vegan, most of the participants felt that they had always been compassionate and caring to nonhuman animals, but they had compartmentalized their compassion. Will described it this way:

We consider ourselves to be animal people, and compassionate, but it was cats and dogs, and pets, and you always felt compassion for them, but that was kind of compartmentalized, in that you didn't really think about the rest of the animal kingdom.

Although most of the participants had always been "animal people," they had not made the connection between nonhuman animals and the food they ate. Lucille, Lanny, Cary, Roger, Lisa, Will, and Maire all expressed amazement that they had not seen the connection. Cary, for example, said,

When I saw hamburgers or steaks, I never put two and two together. I used to eat tongue, which is a Jewish delicacy. I never even knew what it was. It's that disguised. Even though they say the word tongue, I never knew it was that.

Roger, a young body piercer, said that he

... had lots of pets, dogs, cats. I also had an uncle that had a farm where he raised cows. I used to go up to my uncle's farm and play with cows and never made the connection where the meat came from until later in life and I was like, whoa! It's crazy. I loved the cows. I played with the cows.

Lena, atypical of the participants, said that she did not have a strong affection for animals when she was young. Nevertheless, she recalled numerous events involving companion animals during her childhood. Janet observed 
that childhood affection for animals is not exceptional: "I remember I was heartbroken when my pet frog [died]. Absolutely devastated me. But I don't think that's anything unusual. I think other children were the same way."

In summary, most of the participants felt affection for nonhuman animals prior to becoming vegan. Their compassion excluded food animals, because they did not see the connection between the animals they kept as pets and the animals they consumed as food.

\section{Catalytic Experiences}

Catalytic experiences presented information to the participant about animal cruelty and resulted in further action. Participants usually encountered more than one catalytic experience. The catalytic experience triggered one of two responses. Most participants became oriented to further learning about animal abuse. Alternatively, a few participants repressed the information, only to have it resurface at a later time. Most participants who became oriented to further learning did not make an immediate decision. These participants became open to learning about animal abuse and eventually made the decision to give up animal products.

For Lanny and Lisa, the catalytic experience was akin to a religious conversion. Lanny, who had learned about animal cruelty but had not yet decided to go vegetarian, made the decision one day while sitting reflectively in a bottomland pasture. Lanny's life had not been turning out as he thought it might, and he had gone outside to think about it. While he was thinking, he looked up and exchanged a long and pensive gaze with a buck standing on the hill above him. He said,

I just decided not to eat meat anymore. Just all of a sudden, that afternoon, for whatever reason, whether it was a force that made me decide, I don't know. But, it was that instant that I decided to give up meat.

Lisa converted to veganism after watching a video on animal cruelty. She described her reaction to the video this way:

8 - Barbara McDonald 
I watched the video. It was almost like, it was like they say, the curtain was pulled back. The truth was made known. I felt like I had been born again. It was like there is no turning back now. Now I know the cruelty that exists.

The catalytic experience was often, but not necessarily, emotional. An intense emotional reaction to the catalytic experience usually also included a cognitive interpretation that enabled the participant to immediately comprehend, as well as feel, the consequences of the new knowledge of animal abuse. Cognition typically manifested recognition of the power relationship between human and nonhuman animals and was fed by negative emotions, such as guilt, sadness, and anger.

Rarely was a decision made or did learning occur without an interaction between emotions and cognition. Participants often described their understanding as immediate, exemplified by Michelle's statement: "I thought, my God, I just didn't realize what things went on, I really didn't." Although Will had had catalytic experiences before, followed by his repressing information about animal cruelty, he described the cognitive and affective impact of the catalytic experience that resulted in a decision:

Yeah we hit the decision point because once you were face to face with certain facts that, it's like, once you know something you can't not know it. So once we saw those issues, and saw those tapes, and saw the slaughterhouse, and all that, we both, that afternoon, we were sitting there thinking, I have to [go vegetarian].

Janet's second catalytic experience also occurred after she had been learning about animal cruelty. Janet had raised a young mockingbird she called Chirp. One day, Janet left Chirp outside unattended, and one of her dogs killed him. She felt guilt, pain, and grief. That evening while Janet was cooking, she experienced an epiphany: "I cracked an egg and I thought God, that's like a baby Chirp. When that happened, I thought I'm gonna be a vegetarian. And I never went back."

The emotions felt during the catalytic experience were typically negative ones: pain, shock, guilt, sadness, or depression. Lisa, like Michelle, cried as she first learned about animal cruelty. Lena told about her emotional reaction to a video about vivisection, saying, "It affected me so dramatically. It just broke my heart. I have never had [anything] to [have] such an effect."

An Empirical Look at Becoming Vegan - 9 
Emotions seem to have been one of the major defining characteristics of the more memorable catalytic experiences. The decision to become vegan following a period of vegetarianism was more often rational. Will and Maire, for example, spent a lot of time discussing veganism before they decided to make the decision. Maire noted that they "really consternated over [becoming vegan]. That ended up being a big decision, a big conversation, with us." Drew, who examined animal rights literature for about a month before making his decision, said his decision was "mostly rational. I just decided I did not want to contribute to the big... meat machine anymore ... I would not say it was emotional."

\section{The Repression of Information}

Two of the participants heard about animal cruelty but did not immediately respond to it. These participants repressed information about animal cruelty, only to have it reemerge at a later time. Cary, for example, read an article on veal when he was 16 years old. He said the story "hit me hard." Regardless, he put the information into the back of his mind and went on with his life. When I asked him if he was unable to make the change because of family pressure, Cary said,

Not even my family, but my dietary habits. I had never hardly met a vegetarian until college. So, I'm really going way off on a loop if I'm going vegetarian in high school.... I mean you can't go vegetarian if you don't eat vegetables.

Will also found a way to hear, but not respond to, the information on animal cruelty. After learning about the clubbing of Harp Seals, he and Maire began receiving information about animal cruelty in the mail and were slowly becoming active in animal rights. Still, they remained meat eaters. When I asked Will how other people could hear the information but not act on it, he replied,

If they accept this as really being the truth, then there is a moral decision . that has to be made, and if I make that decision, then I'll have to quit wearing leather, I'm going to have to quit eating meat. There's a denial there. But that's very strong. That's very very strong. I mean, people can ration-

10. Barbara McDonald 
alize things very easily. . . So they block it out, and throw a big rationalization in it that says, "Well that's what they say, but that's really not the truth.

\section{Becoming Oriented}

Following a catalytic experience, the participants became oriented to further learning. For some, this orientation included making a decision to go vegetarian or vegan. For others, the orientation was toward learning about animal abuse, how to live a new lifestyle, or both. Becoming oriented provided clear direction for the participant.

When a participant became oriented toward learning about animal abuse or about living a vegetarian or vegan lifestyle, the decision was made consciously and purposefully. As Lanny noted, information about animal cruelty is "not front page news." Learning about animal abuse and how to live a marginalized lifestyle required a clear commitment to learn. Lisa's words describe this commitment: "There's no turning back. Now I know the cruelty that exists. I've been learning and studying and reading ever since." Will and Maire were disturbed by the brutality of the Harp seal hunts, which they learned about from a TV special: "We were really shocked at that, and so we started getting more information about [animal cruelty]."

Becoming oriented required openness to new information and the potential of a new and challenging lifestyle. Lena noted that "you have to start opening yourself up to different things." Cary was struck by the atmosphere of openness at a vegetarian conference he attended: "It just came together ... and people were very open. You know, no blockers on."

\section{Learning}

Becoming oriented and open facilitated learning about animal abuse, how to live a vegetarian or vegan lifestyle, or both. Participants became self-directed, goal-directed learners. Learning about animal abuse and learning a new lifestyle was, in retrospect, guided by an ethical praxis of compassion. As

they learned, participants became more convinced of the moral rightness of their direction. Lisa assuredly pronounced, 
I feel like I have been born again. I feel like I am still on a path to enlightenment. ... It's been a spiritual transformation for me. It was like, yes! God has led me to this.

Participants learned through reading, thinking, talking, and becoming involved in animal rights or vegetarian-related activities. Dialogue was one strategy attempted to learn, teach, or cope with the stress of adapting to their emerging perspective and lifestyle. Often, conversations with others were one-sided, heated, or fraught with the intention to persuade. Many of the participants' families and friends argued with or trivialized the vegetarian or vegan decision, and eventually everyone stopped discussing it. Lanny, Lena, Roger, Lisa, Drew, and Will and Maire described situations where discussion became futile between themselves and family or friends. Drew, not hiding his lingering anger and frustration, shared an experience he had with his parents:

[My wife and I] went out and visited [my parents], and one of the big issues that caused an argument was that they said that [my wife] was giving my mom dirty looks when we were eating. That was totally fabricated.... We never talk about that anymore. I guess they just assume we are some kind of weirdos.

For most participants, lack of support from family and friends caused hurtful feelings. Lanny's family, for example, won't discuss his diet with him anymore. After they argued for a period of time, Lanny sadly concluded, "Yeah, it did hurt a great deal, that they would not accept me and the choices I made." He expounded, using this example:

When I was trying to think of a menu for Christmas day, in talking it over with my parents and my family, it came to the point where I realized they were not going to eat anything I cooked if it was vegan.... They would have nothing to do with it. And so, after a lot of thinking about it and soul searching, I finally decided to go with something that was not vegetarian. It made me feel bad that my values were not important enough to everybody else in my family.

Some of the participants were able to discuss what they were learning with family and friends. This happened most often when the family member or friend was open-minded, sympathetic to the vegetarian or vegan position,

12 - Barbara McDonald 
or was also a vegetarian or vegan. Drew's wife and her grandmother, for example, were vegetarian before Drew met them. Cary's family was supportive, as long as he could prove he was getting the appropriate nutrients. Sean's parents had experimented with vegetarianism, and his words reveal how support may facilitate learning:

For about five years of my life, my parents were very strict vegetarians. I was a young $13,14,15$ years old. I was rebellious. I'm gonna eat meat. They switched back and saw that I was getting a little curious about vegetarianism, and they had so much literature and so many books and so much to say. So it was really helpful, getting that from your parents.

Reading was a primary way of learning for every participant. For those like Michelle and Sean, reading was the main and almost exclusive source of information. Sean explained,

After being vegetarian for less than a year, I was just so curious as to why people take it to a further extent such as veganism. So I started reading a lot of books by John Robbins and Peter Singer, who are some of the top authors that speak on factory farming, animal liberation, and veganism. It attracted me so that I wanted to take it to the next step.

Likewise, Roger learned about vegetarianism and veganism through reading: "That's when I fully made the step. When I read the literature, seeing how the dairy industry was just a destructive machine, so I made that step."

Although much of the literature was in the form of organizational newsletters or brochures, often the impact of a single book was enough to push the participant to further learning or to a decision. Cary's words exemplify this experience:

I read Peter Singer's Animal Liberation. That was the other main source. It really was that, when I was deciding to go vegetarian, definitely, that put me over the top and introduced me to other aspects of agriculture that I also never heard about.

Literature from cookbooks, magazines, and animal rights and vegetarian organizations was used to help the vegetarian and vegan learn everything from the philosophical basis of veganism to how to cook and read ingredient labels. 
Lanny and Michelle learned almost everything by reading cookbooks. Lanny said,

Once I chose to give up meat, my first thought was, I need to learn what else I can cook. So I went to the library, checked out cookbooks to get recipes. And through reading the preface of the cookbooks, I guess that's where I learned the term vegan, not really through anything else. I learned it through reading of the cookbooks and realizing that vegetarian is one thing, but vegan encompasses quite a bit more.

The participants used literature both to learn and to teach. One of their most frequently used ways of educating was giving literature about animal cruelty to others. Participants learned through experience that dialogue was usually ineffective as a method of teaching others. Lena gave an example:

The guy who is my mechanic, apparently I took him something on vegetarianism a while back, but when I was in there the last time he said, You gave me some stuff on vegetarianism a while back. I don't know what I did with it. I really wasn't ready for it then, but could you send me some more stuff. I'm really considering this.

Most of the vegans also learned through some form of animal rights activism. Lena became active in a vegetarian society, where she writes a newsletter and sits on the board of directors. Drew became well-informed by preparing for appearances on radio and television shows. Cary was elected to the leadership of an animal rights organization. Janet lobbies state legislatures for animal protection legislation. For example, Janet and a friend, "along with some animal activists... worked to get [the mandatory spay and neuter law] passed." All these activities required the vegan to be well informed.

\section{Making the Decision to Eliminate Animal Products}

The decision to become a vegetarian or a vegan was made either immediately after a catalytic experience and the orientation to such a lifestyle or following some period of learning. If the decision was made temporally close to the catalytic experience, it was typically more emotional than if it was made after a period of learning. Typically, the vegan decision was made after a period of learning, in which the logical inconsistency of being in favor of

14 - Barbara McDonald 
animal rights but continuing to eat animal products was pondered. As they reflected, talked, read, and became active, the vegetarians-turned-vegan recognized this logical inconsistency between their beliefs and their actions. Lanny explained,

I would think about being a vegetarian but still using milk or still putting cheese in stuff. I would learn more and then decided, where do you draw the line? What's the difference? So why not cut out all animal products, not just in food, but in clothing, in my house, you know, live a truly crueltyfree lifestyle.

Will talked about the relationship between learning and making a decision and how some vegetarians can rationalize not becoming vegan:

An animal doesn't die for this [milk and cheese, for example]. And that's their thing, and they'll come to some point where they may change. But, for us, it's like, you know, when you look deeper, you really see that there are other things behind it, there may be some conditions that's worse than if [the animals] were slaughtered....

The decision to become a vegetarian or a vegan was often seen in retrospect as a fit. Reflecting on the decision to go vegetarian, Will commented that becoming vegan "was something that [we] just had to do." Roger, Lisa, Franz, and Michelle also noted that the decision to be vegan, in retrospect, was inevitable. It felt comfortable, and once made, was final. The vegans in this study felt that their decision to become vegan was in harmony with the greater scheme of things. Franz rhetorically asked, "How could I be spiritual and in harmony with [the animals] if I mistreated any one of them".

\section{The Transformed World View}

The vegans' transformed world views were shaped by a felt connection with nonhuman animals and with nature, the moral rightness of veganism, and by experiencing the world as a vegetarian and vegan. Advocating for the welfare and rights of animals became a dominant purpose of the transformed world view. A central feature of this world view was that animals were no longer viewed as food. Lanny, for example, explained why Indians do not eat cows, even though there is hunger in India: "... they understand that 
that cow is not food. It is a being. And to them, a holy being. So, I would be that way now myself." Janet echoed this sentiment: "When people say 'Isn't it hard?' and I'll say 'No,' because ... I made that connection that it was flesh, that it was not food. I told my mother it's kind of like if I were eating you."

Other features of this world view were that animal protection extended to all areas of life. Major changes had to be made in virtually every area. Maire noted this necessity, explaining that even a vegan's wardrobe and accessories had to be renovated. Lanny, Lisa, Lena, and Franz described an affection for the nonhuman world that extended to caring for nature. Lena commented,

It's like I have a much, much greater respect, certainly for all living things, and of course plant life. I don't even want to pull weeds really. It's sort of like, why do I have to kill this weed? It has a right to be there.

The participants especially expressed a feeling of connectivity with nonhuman animals. Often, that connection was made tangible by the animals' ability to feel pain. Almost every participant mentioned the recognition of this close association with human feeling. Cary expressed this shared ability to feel pain as a bond between human and nonhuman animals: "The dogs, the cows, they certainly feel pain, and yeah, that's a big thing. I mean, it's like a bond."

Sean explained how the feeling of being connected is also a spiritual feeling. He noted that the earth is a "living breathing organism" and that everything on it is "intertwined." He added, "You definitely have a spirituality to it."

The vegans in this study experienced a major shift in their world view. They transformed themselves from people who used animals for convenience, desire, or a perceived necessity to people who, in Lena's words, live by the "general philosophy [of ] harmlessness to all." This philosophy was expressed as an ethical praxis in the way they live their lives. By becoming vegan, they rejected the normative ideology of animal domination by taking a different path and by educating others whenever they had the opportunity. They resisted institutional power by choosing cruelty-free products and by engaging in protests and other activism. They accepted personal relationships by ceasing to argue with friends, family, and acquaintances. Instead, they gently tried to educate when they could, and otherwise they taught by example.

16 - Barbara McDonald 
As they moved through the process of learning to become vegan, participants had to reintegrate themselves into society. Although at times they felt like removing themselves from society, they knew that they could serve the animals best by facing the challenges of being vegan in a sometimes-hostile society. Will said,

To just check out of society, to me, would have less of an impact because you would be written off as a total lunatic and wacko, than living in society and say, this is where I'm driving the stake in the ground and saying this is who I am and these are the choices I'm making.

As marginalized individuals, most of these vegans sought the comfort of solidarity in fellowship with others who feel as they do. But between those times of fellowship, they had to reconcile their philosophy and lifestyle with the need to maintain their marriages, friendships, and family and work lives. Each of the participants in this study had either done this or was in process of doing so. Lisa, the newest of the vegans I interviewed, was continuing to find her place in society. She said, "I'm still confused. I'm still working through all of this." During correspondence for member checking, I wrote in Lisa's narrative,

Lisa feels that others in the movement do not understand her, and she in fact does not fully understand herself. These people, she thinks, have been vegetarian or involved in animal rights for so long that they forget how painful it is at the beginning.

Lisa responded to this passage by underlining and starring the last sentence, and writing "YES!!!" Lisa clearly was working through her feelings and her new knowledge and was working to develop a new identity. She spent a year looking for a new church home that would appreciate and understand her respect for animals. I recently received a letter and a business card from Lisa, announcing her new profession as a reiki healer for people and their companion animals.

Although each story is unique, the vegans followed the same general path from an omnivorous to a vegan lifestyle. A common outcome of the vegan lifestyle was a desire to educate others about animal cruelty. Although the vegans had been through the process, they felt frustrated by the inability to communicate what they had learned. Often rebuffed, or worse, for their efforts, 
they modified their approach to become less invasive and feel more accepted by others.

\section{Discussion}

If one of the goals of vegans is to educate others (Stepaniak, 1998), we must better understand how people learn to become vegan. To better understand the adoption of a vegan perspective, it is important to identify commonalities in the stories of individuals experiencing such change. This research indicates that for these vegans, a common path emerged that, although generalized, also allowed for the telling of individual stories. Models such as the one constructed can guide educational efforts. Before this model is adopted, however, it should be further explored with a larger sample of vegans. One of its limitations is its psychological emphasis. It does not give voice to the rich social milieu in which these vegans learned. Further analysis, which was beyond the scope of this paper, revealed psychological experience inextricably embedded in social relations and the dominant ideology of human superiority (McDonald, in press).

As noted, Mezirow's transformation theory did not explain adequately the learning process of vegans. Transformation theory overestimates the role of democratic dialogue, as these vegans found little opportunity for such dialogue. Transformation theory also pivots on the individual's critical reflection on assumptions. I found little evidence for such reflection in the narratives of these vegans. Finally, as noted in other critiques, Mezirow's transformation theory fails to account for the power of the normative ideology to shape the learning and practice of vegans over time (McDonald, 1999).

\section{Noteworthy Points}

Considering the findings of this research, a number of points are noteworthy. First, this was a study of successful and committed vegans. They are the ones who listened, considered, and accepted the information about animal cruelty as truth. Although two vegans described repressing such information for a time, this research does little to shed light on the important phenomenon of repression. Repression may be a key factor in why many individuals

18 - Barbara McDonald 
hear about animal cruelty but do not act. More research is needed on why and how information about animal cruelty is repressed or ignored by otherwise sensitive and caring individuals.

A second point to emerge from this research is the importance of both logic and emotion in the learning of vegans. For some vegans, logic was the primary cognitive tool used to process information. For others, affect and emotion guided the learning process. For most vegans, the importance of logic and emotion varied across time. More often, emotional trauma appeared initially, followed by rational consideration of information. Veganism, therefore, was more often a rational decision, especially if it had been preceded by a vegetarian lifestyle. For every vegan, however, both logic and emotion played a role in the learning process. Recent reports from neuroscience, such as the work of Damasio (1994), support this finding, highlighting the mutually supportive roles of emotion and reason. Educational efforts for veganism, therefore, should acknowledge the value in recognizing both, while recognizing that individuals will likely respond more to one over the other and, in time, may even change their receptiveness to one over the other.

Another consideration is the importance of openness as a critical characteristic of eventual acceptance. Openness is probably related to an orientation to learn, as well as to the resurfacing of repressed information. It is easy to identify those individuals who are immediately open to learning about veganism and more difficult to know which individuals will eventually allow their repressed emotions and logic into their conscious thoughts. James (1902) described the repression of information as an "unconscious way in which mental results get accomplished" (pp. 202-203). Vegans interested in teaching others should not necessarily be discouraged by an apparent lack of interest or gentle resistance but should provide enough information to plant a seed that may, after a period of dormancy, sprout into the daylight.

\section{The Willingness to Learn}

That initially resistant people can recall repressed information about animal cruelty with a new willingness to learn and that most of the vegans in this study reported a lifelong fondness for nonhuman animals indicate that people may have a biologically- or socially instilled connection to nonhuman 
animals. Janet, one of the vegans in this study, thought that most children feel a bond with nonhuman animals.

Wilson (1993) would agree with Janet. He stated that people have an "innately emotional affiliation ... to other living organisms" (p. 31). Kellert (1996) concurred, but added that this affiliation is a reflection of values rooted in "weak biological tendencies... requiring learning and experience if they are to become stable and consistently manifest" (p. 26). Thus, Kellert argued, affection toward animals may be latent in almost everyone. In American society today, however, he noted that people have less opportunity for learning and experiences that enable those tendencies to be manifested.

If Kellert is correct, a transformation to veganism may be one manifestation of the innate biological affiliation with life. Others, however, are not as sure. Grier (1999) proposed that the child-animal bond was a construction of American Victorian society in an effort to instill the values of kindness and civility in boys. Nevertheless, few would argue that in today's society children typically feel a connection to nonhuman animals. This connection may be rekindled as an adult by a recognition of that bond. As participant Cary noted, the most obvious bond that we have with nonhuman animals is our mutual ability to feel pain.

Another important finding to the vegan movement is the centrality of reading to the learning of vegans. These vegans learned from books, cookbooks, newsletters, magazines, brochures, and other written information. Pivotal to the success of such information is its perception as being true. Recognizing this potential pitfall in educating non-vegans, Phillips (1999) recently called for all vegan-related information to be "impeccably accurate" (p. 1). This study indicates that when people accept animal cruelty information as true, they are compelled to either act on it, repress it, or deal with the moral implications of knowingly supporting cruelty to nonhuman animals.

Finally, learning about veganism was separated into two conceptually different tasks. These tasks correspond to what Mezirow (1991), borrowing from Habermas, called communicative and instrumental learning. Communicative learning has to do with ideas, such as the idea of institutionalized animal cruelty, animal rights, and veganism. Instrumental learning concerns the skills needed to live a vegan lifestyle, such as how to cook, order food in restau- 
rants, and read ingredient labels. Participants indicated the centrality and interdependence of both kinds of learning to their vegan journey. Thus, if others are to be successfully educated about the vegan lifestyle, they must understand the ideological basis for veganism as well as learn the tools for living a vegan lifestyle.

\section{Summary}

This research highlights a number of considerations that may aid vegan educational efforts. First, the path to a vegan lifestyle may be similar across a variety of individual experiences. Although more research is needed to confirm the validity of the presented model, it provides a starting point for understanding how people learn to become vegan. Second, we need a better understanding of why people repress undesirable or uncomfortable knowledge, as well as why it may resurface at a later time. Third, we need to attend to both the logical and emotional aspects of veganism, recognizing the interdependency of both as well as the variable dominance of one over the other. Fourth, although we should look for signs of openness in the people we talk with, we should not avoid giving information to people who are resistant. They may recall our words later with a new willingness to learn. Fifth, we should continue to develop and use written materials of all kinds. We must ensure, however, that our information is accurate, since it is acknowledgment of the truth that spurs change. Finally, we should always provide for ideological learning as well as "how to" put the vegan ideology into practice.

These observations, based on the narratives of twelve vegans, provide a starting point for a more empirically based understanding of learning to become vegan. From a personal perspective, I hope this research will provide guidance to help others with their activism. From a professional perspective, I hope it stimulates increased academic interest in the profound adult learning challenge that veganism represents.

* Barbara McDonald, AUSDA Forest Service 


\section{Note}

1 Correspondence should be addressed to Barbara McDonald, Social Scientist, USDA Forest Service, 320 Green Street, Athens, GA 30602-2044. E-mail: barmac@bigfoot.com

\section{References}

Adams, C. J. (1995). Comment on George's "Should feminists be vegetarians?" Signs, 21 (Autumn), 221-225.

Beardsworth, A. \& Keil, E. T. (1992). The vegetarian option: Varieties, conversions, motives and careers. The Sociological Review, 40 (May), 253-93.

(1993). Contemporary vegetarianism in the U.K.: Challenge and incorporation? Appetite, 20 (3), 229-234.

Damasio, A. R. (1994). Descartes' error: Emotion, reason, and the human brain. New York: Avon.

Dietz, T., Frisch, A. S., Kalof, L., Stern, P. C., \& Guagnano, G. A. (1995). Values and vegetarianism: An exploratory analysis. Rural Sociology, 60 (3), 533-542.

Duda, M. D. \& Young, K. C. (1997). Americans' attitudes toward animal rights, animal welfare, and the use of animals (Report). Harrisonburg, VA: Responsive Management.

George, K. P. (1994). Should feminists be vegetarians? Signs, 19 (Winter), 405-434.

(1995). Reply to Adams, Donovan, and Gaard and Gruen. Signs, 21 (Autumn), $242-60$

Grier, K. C. (1999). Childhood socialization and companion animals: United States, 1820-1870. Society and Animals, 7 (2), 95-120.

Hamilton, M. B. (1993). Wholefoods and healthfoods: Beliefs and attitudes. Appetite, 20 (3), 223-228

James, W. (1902/1936). The varieties of religious experience: A study in human nature. New York: The Modern Library.

Kellert, S. R. (1996). The value of life: Biological diversity and human society. Washington, DC: Island Press/Shearwater Books.

Krizmanic, J. (1992, January). I really want to but . . Vegetarian Times, 173, 34-40.

McDonald, B. (1998). A comparison of Mezirow's transformation theory with the process of

22 - Barbara McDonald 
learning to become an ethical vegan. Unpublished doctoral dissertation, University of Georgia, Athens.

1999. Power and the transformational learning of ethical vegans. Adult Education Quarterly, 50 (1: 5).

Mezirow, J. (1991a). Transformative dimensions of adult learning. San Francisco: JosseyBass.

(1995). Transformation theory of adult learning. In M. R. Welton (Ed.), In defense of the lifeworld (pp. 39-70). Albany: State University of New York Press.

(1998). Transformation theory of adult learning - Core propositions (Unpublished paper ). New York: Teachers College, Columbia University.

Moustakas, C. (1990). Heuristic research: Design, methodology, and applications. Newbury Park, CA: Sage.

Phillips, C. (1999). Getting our facts straight. Vegan Outreach, 8 (3), 1.

Rozin, P., Markwith, M., \& Stoess, C. (1997). Moralization and becoming a vegetarian: The transformation of preferences into values and the recruitment of disgust. Psychological Science, 8 (March), 67-73.

Stepaniak, J. (1998). The vegan sourcebook. Los Angeles: Lowell House.

Strauss, A. \& Corbin, J. (1990). Basics of qualitative research: Grounded theory procedure and techniques. Newbury Park, CA: Sage.

Walker, C. (1995). Meet the new vegetarian. American Demographics, 17 (January), 9-11.

Wilson, E. O. (1993). Biophilia and the conservation ethic. In S. R. Kellert \& E. O. Wilson (Eds.), The biophilia hypothesis (pp. 31-41). Washington, DC: Island Press/ Shearwater Books.

An Empirical Look at Becoming Vegan - 23 